\title{
Potassium Nitrate
}

National Cancer Institute

\section{Source}

National Cancer Institute. Potassium Nitrate. NCI Thesaurus. Code C82074.

A crystalline salt, KNO3; a strong oxidizer used especially in making gunpowder, as a fertilizer, and in medicine. 